\title{
O DOCUMENTÁRIO LONGITUDINAL: A IMPORTÂNCIA DE FILMAR COM TEMPO
}

\begin{abstract}
Amaya Sumpsi ${ }^{1}$
Em forma de diário de filmagem, a autora percorre os nove anos que passaram desde que teve o primeiro contacto com a comunidade que depois veio a filmar até à estreia do documentário e à devolução das imagens aos sujeitos filmados. No texto, a autora analisa o papel da antropologia no processo de construção do filme e mostra, baseando-se na sua própria experiência, as vantagens e desvantagens de filmar os mesmos sujeitos ao longo de tanto tempo.

Palavras-Chave: documentário longitudinal; slow filming; antropologia visual
\end{abstract}

\section{INTRODUÇÃo}

\begin{abstract}
Longitudinal docs are the most deeply satisfying form. Spending years following a story is the ultimate act of filmmaking discovery, because you don't know where the journey is leading, no matter how perceptive you think you are. Indeed, you hope and pray you'll be surprised, because if you stick with interesting people long enough, they'll always surprise you - that's the beauty of human nature.
\end{abstract}

James $2008^{2}$

\footnotetext{
1 UNL-FCSH, Lisboa, Portugal. Contacto: amayasumpsi@gmail.com

2 Steve James nasceu em América em 1955, e graduou-se pela Southern Illinois University Carbondale. Cedo começa a colaborar com a Kartemquim Films, uma produtora sem fins lucrativos sediada em Chicago. Além de produtor, é realizador de documentários independentes. Entre os seus trabalhos destacam-se o documentário "Stevie", que recebeu o prémio Joris Ivens do Festival Internacional de Documentário de Amsterdam (2002), e "Hoop", vencedor do prémio do público no Festival Sundance (2004). O artigo referenciado neste trabalho foi publicado após a estreia do seu documentário "At the Death house door" (2008), um filme sobre Carroll Pickett, juiz de execução da unidade prisional "Huntsville", no Texas. Pickett presidiu a mais de 95 execuções durante 15 anos. Inicialmente a favor das execuções, tornou-se um activista contra a pena de morte.
} 
"Apanhados na rede" é a minha primeira longa-metragem. ${ }^{3}$ Dediquei-me a este projecto, filmado em Porto Formoso, uma pequena aldeia de pescadores da costa norte da ilha de São Miguel, no arquipélago dos Açores, durante 9 anos. O passar dos anos, embora inicialmente involuntário, acabou por se tornar fundamental na construção do mesmo e acabou por ser o seu leit motiv. O processo de realização deste documentário, que requereu longos períodos de convívio, observação e interacção com os sujeitos, prolongados por nove anos, fazem com que este documentário, e a dissertação de mestrado que o acompanha, sejam considerados um estudo etnográfico longitudinal. $\mathrm{O}$ documentário visa acompanhar os mesmos indivíduos durante um longo período de tempo, como num trabalho típico de observação. Observam-se os elementos, evitando ao máximo a manipulação dos fatores que possam alterar as variáveis de interesse, procurando compreender as mudanças sociais melhor do que seria possível por meio dos estudos transversais. Deste modo, consegue-se estabelecer relações de causa-efeito mais facilmente ao centrar o olhar na trajetória de vida dos indivíduos incluídos no trabalho, o que permite uma compreensão mais profunda sobre as relações entre as variáveis observadas como, por exemplo, entre nível educacional e empregabilidade, entre formação profissional e atuação da área, etc. Por outro lado, enquanto os estudos transversais detêm um carácter quantitativo, os estudos longitudinais baseiam-se essencialmente num método qualitativo. $\mathrm{O}$ método qualitativo (Richardson 1999: 80) "caracteriza-se pela condição de descrever a complexidade de determinado problema, analisar a interação de certas variáveis, compreender e classificar processos dinâmicos vividos por grupos sociais". É de salientar também que esta abordagem pode contribuir para o processo de mudança de determinado grupo e possibilitar, mais profundamente, o entendimento das particularidades do comportamento dos indivíduos. Esse foi o objectivo do documentário e da dissertação que o acompanha.

A passagem do tempo é acompanhada por mudanças, naturalmente. Ao longo de todo este tempo não só as pessoas que filmei se transformaram, mas também eu. Durante estes nove anos em que acompanhei a aldeia, vi jovens crescerem e tornarem-se homens, vi outros adoecerem e alguns morrerem, vi pessoas a partir e outras a chegar. Eu também me transformei: fui viver para o campo, depois para a cidade, arranjei novos trabalhos, voltei a estudar, tive uma filha. Mas há neste filme algo mais do que querer acompanhar o ciclo de vida das pessoas, as suas mudanças físicas, sociais, de costumes, de crenças, a sua mudança interior. Porque além do tempo biográfico, o meu e o dos habitantes, existe também um outro tempo.

Trata-se do tempo colectivo da comunidade, aquele tempo histórico que vai definindo os seus caminhos. Porque, enquanto eu estava a filmar na aldeia, tiveram lugar uma série de acontecimentos que provocaram entre os habitantes uma discussão profunda e enérgica sobre o abandono ou a perpetuação de uma identidade (neste caso a transformação ou manutenção da paisagem que dá nome à aldeia, o Porto -de pesca- Formoso), discussão esta que os levou, inevitavelmente, a questionarem a sua própria identidade. Pesca? Paisagem? História? Tudo estava a ser posto em causa. O passado, o presente, o futuro e as suas variantes; o progresso e as diferente propostas, muitas vezes opostas, para o pôr em prática. Este é um documentário que recolhe, além de tudo, o intervalo de tempo que costuma preceder as grandes transformações de uma

3 Este foi o primeiro título do documentário, associado ao título da dissertação teórica que acompanhava. Embora este título tivesse sentido do ponto de vista antropológico, mais tarde decidi mudá-lo, para evitar possíveis mal entendidos, tanto entre a comunidade onde foi filmado, que o poderia interpretar negativamente, como pelo público em geral, que parecia pensar em "rede" antes no sentido virtual da palavra do que no sentido literal. O título escolhido foi "Meu pescador, meu velho", em honra a uma frase dita por um dos protagonistas do filme e grande amigo, que nos deixou recentemente. 
comunidade, tempo este fértil em discussões de conceitos e significados, desejos e nostalgias, passados e futuros. Na praça, nas "tascas", no porto, em casa, todos participam. Durante esse transe de transformação acontecem momentos únicos, situações que brilham com um significado especial e que têm a capacidade de evocar toda a intensidade do transe. O filme projecta os tempos biográficos sobre um outro tempo, prévio à transformação. A mudança (minha), sobre a mudança (deles), sobre a mudança (da comunidade).

Embora, como veremos, a antropologia fosse fundamental na construção narrativa do tempo e na criação de uma linha discursiva do meu documentário, é importante salientar para perceber a arqueologia deste projecto, que só 5 anos depois de eu ter começado a filmar a comunidade é que a antropologia, como método e como saber, começou a fazer parte do processo criativo. A antropologia serviu para analisar o material já filmado em retrospetiva e para orientar as últimas filmagens e o processo de edição final. Assim, no decorrer destes nove anos existem três momentos muito diferentes entre si, que não só não se excluem, como se complementam. Estes três olhares são importantes para perceber a construção autoral do filme, pois cada um destes momentos está marcado pelas circunstâncias em que eu acompanhei a comunidade, isto é, pelo papel que fui adoptando perante os sujeitos que observava. Cada um dos momentos estabelece uma perspectiva, uma metodologia e objectivos diferentes que surgem de um "Eu" particular, mas que se reúnem num único trabalho, que é este documentário. Se num primeiro momento, em 2003, eu me posicionei perante a comunidade como um "visitante", num segundo momento, entre 2004 e 2008, acrescentei o olhar de "documentarista" e só num terceiro momento, entre 2009 e 2012, é que adoptei a perspectiva da "antropologia”. Cada um destes três momentos manifesta-se na construção deste filme simultaneamente, mas de uma maneira diferente: o "eu visitante" a um nível emocional e subjectivo; o "eu documentarista" a um nível narrativo e visual; o "eu antropólogo" a um nível científico e objectivo.

$\mathrm{O}$ artigo que aqui apresento pretende ser o diário pessoal desta viagem ao longo do tempo: quando se passam anos a filmar no mesmo lugar e com as mesmas pessoas, é inevitável que as histórias pessoais se misturem com a profissional.

\section{I}

Comecemos pois pelo início. Em 2001, licenciei-me em Literatura e Línguas Hispânicas e, ao mesmo tempo, em Realização de Cinema e Televisão em Madrid. Um ano mais tarde mudei-me para os Açores e em 2003 instalei-me na costa norte da ilha de São Miguel, depois de ter arranjado trabalho como professora de fotografia para uma produtora cultural da ilha. Nesse ano conheci o Dídio, um vizinho natural de Ribeira Grande, que trabalhava para a EDA (Electricidade dos Açores) e que passava os fins-de-semana na aldeia vizinha, Porto Formoso, na companhia dos pescadores. Atraída por este mundo, tão diferente do meu, comecei a acompanhar as suas visitas, a sair à pesca de vez em quando, a passar as tardes na tasca, entre rodadas de cerveja. Nesta altura a minha motivação era unicamente pessoal, não tendo outro objectivo a não ser o de perceber estas pessoas e partilhar com elas o meu tempo livre. Sem câmara, e sem o conhecimento antropológico de que disponho actualmente, movimentava-me pela comunidade ao sabor dos meus instintos e apetências, estabelecendo relações por empatia e observando aquilo que me chamava a atenção. Sem o objectivo de procurar uma imagem forte e sem a 
intenção de delinear ou contextualizar um texto académico, eu era apenas eu, reagindo ao deslumbramento que costuma provocar o conhecimento de uma forma diferente de estar na vida.

Sendo eu uma pessoa que sempre se sentiu atraída pela narrativa da imagem, não passou muito tempo até começar a sentir o impulso de registar em imagens estas vivências, sobretudo tendo em conta o acesso privilegiado a esta comunidade que conseguia ter através do Dídio. Com este objectivo, em Junho de 2004 decidi investir na minha primeira câmara de filmar. Era (e é) uma Sony PDX 10P que grava em DVCAM e 16:9 e, apesar da sua aparência de câmara doméstica, produzia a imagem de uma semiprofissional. Foi pelo seu tamanho e aparência discreta que a escolhi: com ela poderia estar a filmar sem chamar muito à atenção, como uma pessoa qualquer que filma para registo pessoal, evitando dentro do possível a intimidação óbvia que decorre do uso destes aparelhos e que é maior quanto maior o dispositivo. Com ela, dediquei-me a registar imagens e detalhes das artes de pesca antigas, apenas praticadas pelos mais velhos da aldeia, com a intenção de perpetuar a memória destas práticas: era a apanha do caranguejo e do camarão, a pesca em linha de cavalas. Mas também comecei a filmar momentos da vida quotidiana destes homens, jantaradas do grémio, a venda do peixe pela aldeia, o dia-a-dia no porto, a chegada à terra, as festas populares. Embora a preocupação estética estivesse presente, nessa altura, e tendo em conta a espontaneidade do que filmava, a minha intenção era apenas registar como imagem de arquivo. Neste sentido, estas filmagens estavam próximas daquilo que pretendia o filme etnográfico na sua origem e que durante grande parte do seu percurso defendeu Margaret Mead: usar a câmara de uma forma completamente objectiva, como dispositivo de recolha de informação científica, com o intuito de preservar o registo de fenómenos culturais ameaçados de extinção devido as mudanças sociais e económicas. Como diria Mead (1995: 9-10) "this filmic $[. .$.$] not need to be motivated by any theoretical purpose: the important thing was to get it$ done before the customs in question disappeared for ever". Algumas destas sequências, gravadas no início, foram incluídas no documentário final.

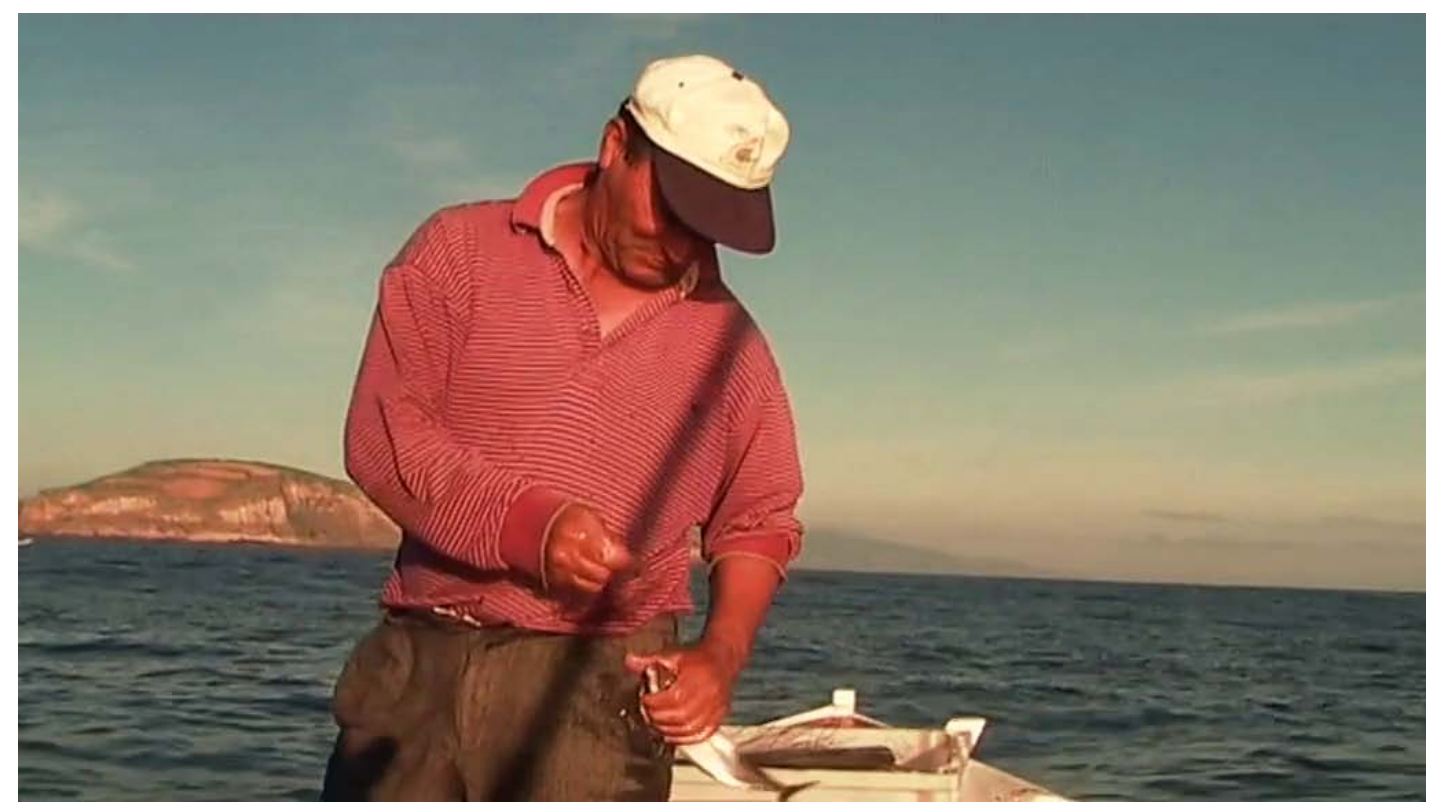

Excerto 1: Registo da pesca da cavala filmada em 2004 e incluída no documentário final 
O panorama mudou, porém, em 2005, momento em que se deu o ponto de inflexão do meu projecto. Foi na noite de Carnaval desse ano que uma onda, que a população de Porto Formoso descreve como um "tsunami", atingiu o porto de pesca da aldeia, destruindo dois barcos. ${ }^{4} \mathrm{Eu}$ não estava na altura a viver na ilha, pois tinha mudado para Lisboa no outono de 2004. Assim, só soube do acontecimento no verão seguinte, quando fui lá passar férias e revisitar os amigos. $\mathrm{Na}$ aldeia, a conversa desse verão girava em torno das consequências do catastrófico acidente. Os mestres estavam a construir barcos novos, de maior envergadura, mas toda a gente falava do quão difícil seria trabalhar com eles no pequeno porto natural da aldeia, construído sobre a areia. Quase como num efeito dominó, este incidente tinha levantado uma série de questões que já não diziam respeito apenas aos pescadores, mas sim a todos os habitantes da aldeia, abrindo assim o caminho que precipitaria a transformação. Ampliar o porto com uma doca em cimento, para dar continuidade à atividade piscatória tradicional e identitária desta comunidade, modernizando-a, ou preservar a beleza natural e o valor histórico do antigo porto, ambos também com valor identitário e, ainda, com potencial para atrair turismo? Existe uma solução intermédia? Qual destes modelos poderá trazer maiores benefícios à comunidade? Podem conviver ambos? Qual o peso do valor económico e do valor simbólico destas dimensões identitárias? Estas e outras questões discutiam-se, de manhã à noite, no café, no porto, na praia, nas casas, na Junta de Freguesia, na Ribeira Grande, na internet. Este episódio tinha posto em relevo tensões que, se antes apenas se percebiam subtilmente, agora estavam à flor da pele. Eu fui apanhada de surpresa, mas não demorei a perceber que algo de importante se estava a passar. Parecia como se frente os meus olhos a aldeia se estivesse a repensar e a reconfigurar, e eu tinha acesso a esse processo de transformação graças à relação que tinha criado com o lugar e com os habitantes nos anos anteriores.

Porém, houve um acontecimento em particular que me fez realmente acreditar que, por detrás destas conversas, havia uma grande história para contar, uma história pessoal mas também universal. Nas minhas primeiras incursões sobre esta discussão pública, costumava perguntar às pessoas que estavam contra a construção do porto quais eram os seus motivos. Muitos habitantes falavam-me da importância de manter a paisagem natural para atrair o turismo e, entre estes discursos, falavam com veemência da importância das ruínas de um "castelo", património da aldeia, que se encontravam junto ao porto e que seriam destruídas caso as obras avançassem. Mas de que castelo estavam a falar? Eu já tinha estado muitas vezes no porto e nunca tinha visto ali nenhum castelo. Acompanhada de um pescador, desci ao porto com a minha câmara à procura de tal património. Nós já tínhamos chegado, mas eu continuava em busca do "castelo". O contraste das discussões apaixonadas em defesa do "castelo" com o que encontrava perante mim era assombroso: eu só via umas pequenas ruínas que não deixavam adivinhar nada mais do que algumas pedras, uns pequenos muros que se confundiam com os calhaus, uma pequena estrutura abandonada, um rascunho insignificante de um passado indefinido. Depois desta visita decidi aprofundar o sentimento que esta ruína produzia nas pessoas da aldeia, os argumentos que utilizavam para a defender ou para a desprezar. Além de ser evidente que ninguém na aldeia tinha muito claro a origem histórica do "castelo", nem o porquê deste nome, a valorização dife-

4 Provavelmente influenciados pelo mortífero tsunami que teve lugar no Oceano Pacífico apenas uns meses antes, em Dezembro de 2004. 
rente que se fazia dele manifestava de forma indirecta perspectivas divergentes sobre a natureza, a história, o património, o turismo e o futuro da aldeia.

O património não existe per se, fora de um discurso de valorização e de apreciação que recai sobre um conjunto de bens e referentes simbólicos que se constituem como património. [...] O que é considerado digno de valorização e de preservação altera-se conforme os contextos e conforme os momentos. Portanto o que muda não são os bens em apreço, mas antes a valorização social que sobre eles recai.[...] o que importa é o processo de valorização, não os bens de património em si. (Elsa Peralta 2008: 75)

Ao falarem do castelo, os argumentos que os habitantes expunham a favor ou contra ultrapassavam os limites da aldeia e com uma lucidez assombrosa abriam-se às controvérsias globais sobre a relação com o passado, a vivência do presente e o desenho do futuro. $\mathrm{O}$ "castelo" passou a ser, rapidamente, mais uma personagem do meu filme e, ao longo dos anos, foi ganhando espaço no elenco de protagonistas.

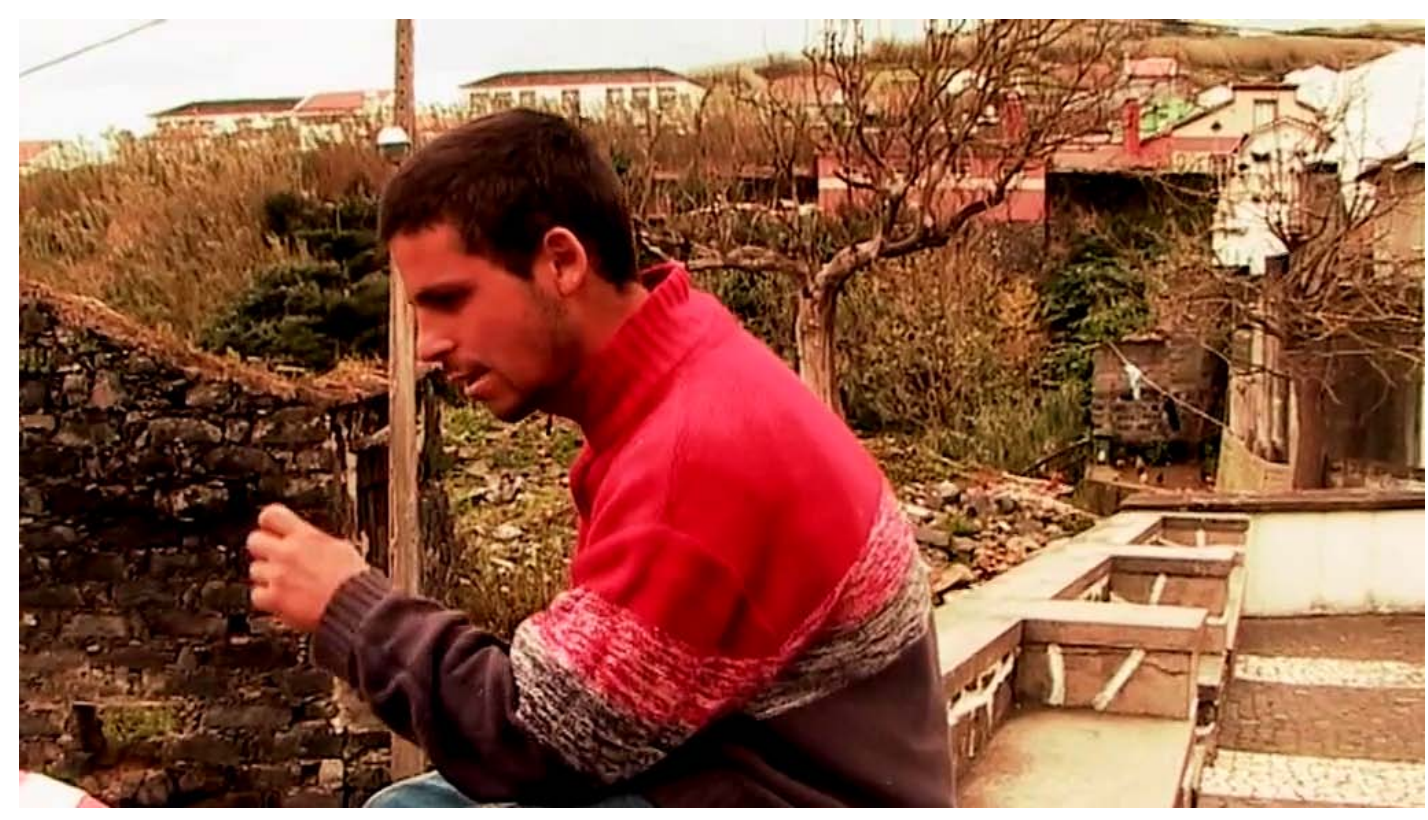

Excerto 2: Fragmento da discussão captada entre dois habitantes (César e Sr. João) acerca do valor patrimonial, natural e estético do "castelo".

Quando voltei a Lisboa, depois desse verão de 2005, sabia já que as filmagens que tinha começado nesse verão teriam de ter continuação, pois o processo de transformação seguiria o curso natural da história, prolongando-se por anos (como depois se viria a confirmar). A partir desse momento, as visitas a Porto Formoso tinham um novo objectivo: fazer um documentário que acompanhasse este processo. Investi nalgum material extra, como um microfone de melhor qualidade, protectores de vento e lentes: a preocupação na estética, na qualidade de imagem e de som aumentou: o tema merecia. $\mathrm{O}$ meu objectivo tinha deixado de ser apenas o de registar, para contar a transformação destas pessoas, deste porto, deste castelo, desta aldeia. Voltei a Porto Formoso em 2006, 2007 e 2008, enquanto a aldeia continuava a pensar-se e a transformar-se. Costumava fazer uma ou duas viagens por ano, uma no verão e outra no inverno. Esse registo 
acabou por ser fundamental para este trabalho, pois a câmara acompanhou-me em todos os momentos, captando não só conversas, discussões e opiniões, mas também o meu dia-a-dia na aldeia. Seguindo os acontecimentos, filmei a construção dos novos barcos, as novas dificuldades do porto, as discussões no miradouro e na tasca. Marquei e filmei entrevistas individuais e colectivas com os pescadores, mas também com outros habitantes e com agentes externos e representantes de instituições envolvidos no processo enquanto a discussão se ia desenrolando ao longo dos anos. ${ }^{5}$ Embora nesta altura eu ainda não tivesse tido contacto com as teorias antropológicas nem com a metodologia do trabalho de campo, as questões que ia colocando aos habitantes e a forma como orientava as entrevistas mostravam já, de forma intuitiva, uma sensibilidade antropológica.

Durante estes anos, a situação foi sendo cada vez mais difícil para os pescadores. Enquanto a aldeia discutia, as decisões politicas sobre o porto estavam cada vez mais bloqueadas, adiando a projecção de qualquer obra. Perante a dificuldade de trabalhar com barcos tão grandes sobre a areia, em 2007 dois dos mestres que eu acompanhava desistiram: o mestre Eiró vendeu o seu barco e foi trabalhar para as obras e o mestre Paulo Jorge emigrou para as Bermudas. Embora esta situação fosse enriquecedora do ponto de vista da narrativa dramática da realidade, nesta altura eu já tinha uma relação com eles muito próxima e senti, com eles, toda a sua tristeza e ao mesmo tempo uma grande frustração com a inércia política ali mostrada. Agora, mais do que nunca, acreditava na importância de contar esta história. A dificuldade residia em encontrar o frágil equilíbrio entre o companheirismo e respeito pela amizade criada com as pessoas a quem filmava e a necessidade de mostrar uma realidade mais abrangente e o mais imparcial possível. James (2008) resume assim esta experiência:

\footnotetext{
Then there are the human relationships of longitudinal filmmaking. If you spend years filming people, they will grow to be something more than just a "subject." I've never thought of myself as a journalist, so I don't wrestle over notions of "journalistic objectivity" and dispassionate observation, but that doesn't prevent me from struggling with my desire to document a subject's life in an honest way and still feel like a friend. When misfortune happens to people in your film, it's usually good for the film, but not necessarily so for your relationship with them, or for how you feel about yourself. In short, you can feel like a leech on another's misery. Someone once asked me, "What's more important? To make a great film, to make an honest film, or to have a great relationship with your subjects at the end of the film?" They're not mutually exclusive, but every experienced longitudinal filmmaker I know asks him or herself that question. Handled right and with a bit of luck, the misfortune you document should bring you closer to your subjects and make both of you feel that you have an important story to tell.
}

\section{V}

Parece-me importante trazer a este texto algumas questões de produção. Este documentário foi feito sem nenhum apoio financeiro. As filmagens começaram como um pequeno projecto pessoal: eu, a minha câmara e o microfone. A história foi ganhando força e ficando cada vez mais interessante, mas tendo eu estabelecido já uma forma de trabalho com as pessoas filmadas, baseada na intimidade e no registo informal, não queria complicar o processo: os financiamentos institucionais costumam trazer uma burocracia e uma complexificação das equipas envolvidas,

5 Foram entrevistados, entre outros, o presidente da Junta de Porto Formoso, o Sr. Emanuel Faria, o dirigente sindical Liberato Fernandes e Luís Rodrigues especializado em assuntos do mar na ilha de São Miguel. 
que desejava evitar. Além disso e tendo em conta que a minha história apenas o tempo a contaria, era difícil argumentar o valor do meu projecto. Como refere James (2008):

As fulfilling as longitudinal filming is, it's also hard. It's hard to find funding, because many broadcasters like to know what they're paying for in advance. Even when you get funded, it's hard for filmmakers to juggle their obsession with filming everything with their need to otherwise make a living: spending four or five years filming 200 days on a documentary budget doesn't work out to a very good "day rate."

Assim sendo, mantive até ao fim o mesmo "modus operandi" de produção: juntava férias com filmagens, pagava todas as despesas (que mantinha no mínimo), dormia em casa de amigos ou na praia ao pé dos barcos, pedia ajuda aos colegas e vivia (e vivo) do meu ordenado como professora de espanhol.

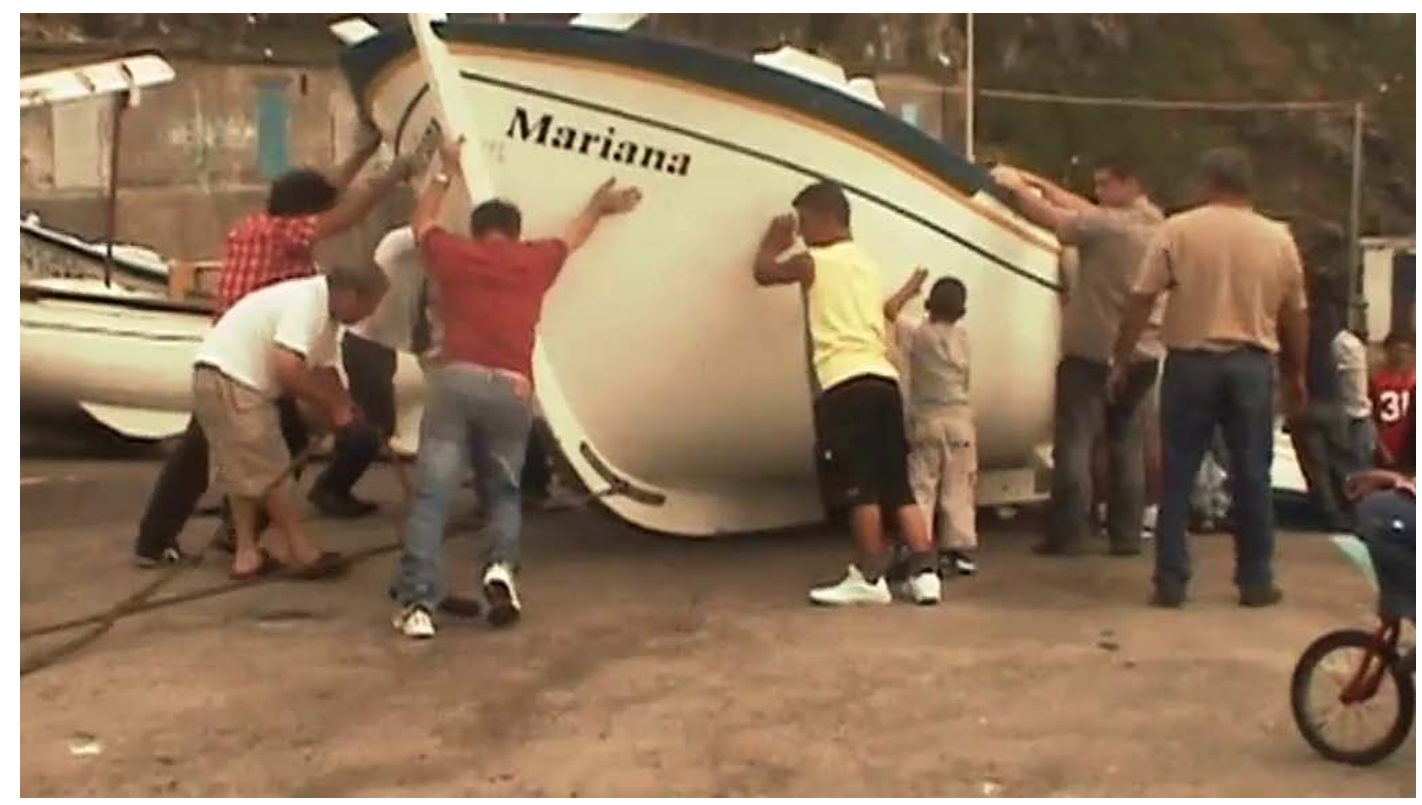

Excerto 3: Imagens da primeira saída ao mar dos barcos novos captadas por André Almeida, que fazem parte e são essenciais para a narrativa visual do documentário.

Porém, quanto à forma de filmar, tive de reequacionar a situação. Dado que as discussões, entrevistas e filmagens se tinham multiplicado, eu não conseguia continuar a dirigir as conversas, compor os planos e controlar o som ao mesmo tempo. Mais de uma vez gravei rostos cortados ao meio, conversas fora do campo, planos queimados, ora porque estava absorta na entrevista ora porque estava a nivelar o som. Depois de rever alguns destes registos e percebendo a necessidade óbvia de ajuda, mas também a ausência total de financiamento, pedi ao meu namorado Eduardo para me ajudar. Ele costumava acompanhar-me muitas vezes à aldeia, conhecia bem as pessoas, tinha feito amigos e tinha acompanhado a história desde o início. Se até agora tinha assistido apenas como observador, passou a ter o papel de assistente. Quando me queria centrar na composição de planos, ele fazia as perguntas que me interessavam e, muitas vezes, trazia outras novas. Ajudava frequentemente com o som e, pontualmente, quando se tratava de uma entrevista que me exigia maior concentração, eu compunha o plano mas ele filmava. Eu, como Jean Rouch, penso que, em documentário, o realizador deve ser o seu próprio operador de câmara (Ribeiro 2007:40), pois só ele tem o conhecimento suficiente sobre os seus objectivos e interesses e a relação intima com os sujeitos para poder reagir com a câmara a situações improvisadas e espontâneas. Com o tempo, os habitantes da aldeia acostumaram-se a nós os 
dois e à câmara e assim fui acumulando horas e horas de material audiovisual. Tendo em conta a boa relação anterior de Eduardo com os pescadores e a sua ligação de género e de interesses (na pesca, na aldeia, nas tardes de tascas), a sua participação com um papel mais activo acentuou o ambiente de informalidade e intimidade das filmagens.

Além de nós os dois, tive de pedir numa ocasião a um amigo, que não era de imagem, que fosse filmar um acontecimento, pois não tinha dinheiro, nem férias, para irmos nós: tratava-se do dia em que os novos barcos saíram ao mar pela primeira vez, para ir de Rabo de Peixe, onde tinham sido construídos, até ao Porto Formoso, onde seriam baptizados. Neste caso o valor do registo sobrepõe-se às preocupações estéticas e quaisquer outras e a importância da sequência ficou patente no documentário.

\section{VI}

O facto de apenas poder ir filmar uma ou duas vezes por ano fazia-me oscilar entre o entusiasmo mais apaixonado pelo projecto e o esquecimento absoluto, perdido entre as preocupações do dia-a-dia de quem vive e trabalha em Lisboa. O processo parecia repetir-se: cada vez que voltava de uma viagem a Porto Formoso, com mais material, ganhava novo entusiasmo e voltava a acreditar na história. Sentava-me na mesa de edição e ia organizando o material, seleccionando partes das entrevistas, melhores imagens. Tentava montar sequências, dar ordem às imagens, coerência aos depoimentos, mas tinha imenso material e tudo parecia interessante, essencial. Eu não conseguia ter distância e o bloqueio ia crescendo: era demasiada informação, demasiadas reflexões para incluir apenas num filme. Para distanciar-me do material, pedi ajuda a minha colega e editora Rita Figueiredo, pois ela tinha muita experiência em edição e tinha feito todo o tipo de trabalhos. Com ela consegui editar algumas sequências do início, mas acabámos por desistir: os habitantes de Porto Formoso falam um dialecto micaelense fechado, que dificilmente é percebido pelos portugueses continentais. ${ }^{6}$ Isto dificultava extremamente o trabalho da Rita: sem perceber o que diziam, era muito difícil associar ideias, montar sequências coerentes e construir uma narrativa.

Ainda assim, havia outro elemento que bloqueava o processo de edição audiovisual do material: eu queria que os habitantes contassem a sua própria história, evitando ao máximo a minha intervenção e apagando do filme a minha presença. A tendência em minimizar e mesmo negar o carácter autoral do documentário etnográfico é antiga. Até à década de 70 o documentário etnográfico era percebido como a retórica da verdade e da objectividade, mas, como refere Henley (2009), em meados desta década começaram a surgir novas perspectivas na literatura inglesa da antropologia visual que apontavam para outras direções. Conceitos como "Reflexividade" e "vídeo participativo" refletiam a consciência de que "an ethnographic film does not provide an objective 'scientific' account of the world but is rather the product of the subjective vision of the film-maker that he or she has developed through their relationship with the subjects" (ib.idem:10-11).

6 O dialeto micaelense falado pelos porto formosenses é especialmente difícil de perceber para quem vive no continente e até noutras ilhas dos Açores. A barreira linguística entre mim e eles foi superada com gestos no início, até que fui aprendendo a língua com horas de convivência. Porém e depois de fazer vários testes, percebi que seria necessário legendar o documentário na norma portuguesa do continente para poder ser percebido fora da aldeia. 
Eu na altura não tinha conhecimentos sobre o filme etnográfico nem a sua história, nem sobre a área de estudos da antropologia visual, pelo que chegar à mesma conclusão custou-me muitos anos e numerosas tentativas.

\section{VII}

Em 2008 apenas consegui ir aos Açores para fazer um outro trabalho: uma tradução simultânea no parlamento regional, situado em Faial. Aproveitei a viagem para fazer uma paragem de um fim-de-semana em São Miguel e passei uma tarde pela aldeia para saber das pessoas. Consciente de que não teria tempo para filmar, aproveitei para mostrar as sequências iniciais que tinha editado com a Rita aos pescadores e amigos que encontrei pela aldeia. Para o fazer, juntámo-nos na pequena loja do Viana, ponto de encontro habitual e mostrei as sequências numa pequena televisão. Como não foi combinado com tempo, apareceram só alguns: os clientes habituais da tasca, que apareciam no filme em segundos planos, os músicos que põem música ao filme com a sua guitarra e alguns familiares dos protagonistas que, nessa altura, estavam fora da aldeia. Ao verem-se retratados na mesma televisão em que costumavam ver os programas da tarde, as telenovelas, os telejornais e o futebol, ficaram em silêncio. Mas rapidamente começaram a rir, a comentar, a assinalar esta ou aquela pessoa, e ouviam atentos o que lá se dizia. Para mim foi reconfortante, mas apesar de sentir a sua alegria, sentia sobre mim o peso do bloqueio, cada vez maior e a nuvem de saber que o projecto parecia estar guardado na gaveta definitivamente.

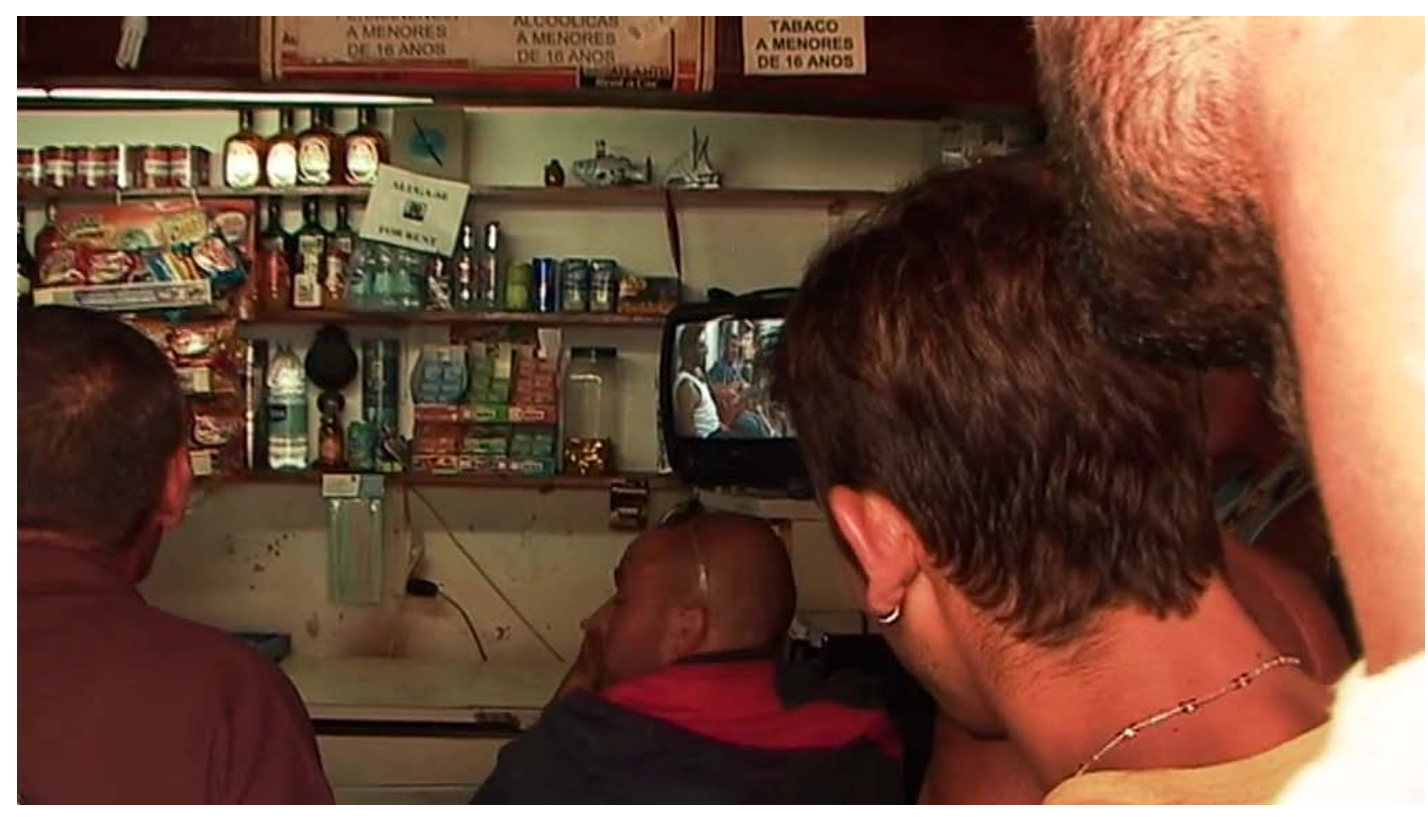

Excerto 4: Visionamento da primeira versão com alguns dos participantes no documentário, incluído na montagem final.

Um ano mais tarde decidi voltar a estudar e comecei a pesquisar mestrados que me pudessem interessar. Nesta pesquisa, descobri o mestrado em Antropologia e Culturas Visuais da Universidade Nova de Lisboa, coordenado pelo professor João Leal e a professora Catarina Alves Costa: este mestrado poderia ser uma ferramenta que me ajudasse a desbloquear o filme que há tantos anos tinha começado. Eu na altura apenas tinha ouvido falar em antropologia e 
tinha uma vaga ideia do que era, mas de alguma maneira associei a antropologia ao meu filme. Seguindo a minha intuição, inscrevi-me. Como referi anteriormente, foi através deste mestrado que tive o meu primeiro contacto com a perspectiva antropológica e foi através desta nova janela que muito do meu trabalho ganhou um novo sentido: os seminários que segui, os textos que li, os filmes que vi e as discussões que acompanhei fizeram-me olhar para o meu trabalho de uma nova forma. Em primeiro lugar, percebi que a experiência que tinha vivido em Porto Formoso até à data podia tornar-se, sem muitas alterações, no diário etnográfico do trabalho de campo, pois as premissas mais importantes deste trabalho, tal e como as tinha esboçado Malinowski (1922) estavam presentes. Em primeiro lugar a sensibilidade etnográfica. Esta sensibilidade, que Malinowski define como a capacidade de saber ouvir, partilhar, simpatizar, apreciar a companhia e respeitá-la, mostrando boas maneiras, esteve presente ao longo das minhas visitas e estadias na aldeia, manifestando-se na forma como me relacionei com a comunidade. $O$ trabalho prolongado de campo e o conhecimento da língua foram também apontadas por Malinowski como duas premissas básicas do Método Etnográfico. ${ }^{7}$ Existe ainda um terceiro ponto essencial no Método Etnográfico de Malinowski: (1922: 23) "o investigador deve guiar-se por objectivos verdadeiramente científicos e conhecer as normas e critérios da etnografia moderna”. Pelos motivos que já apontei, não cumpria este requisito: entre 2003 e 2009 não tinha por objectivo produzir qualquer trabalho científico nem conhecia as bases teóricas da antropologia. Porém, na sua revisão do Método Etnográfico, Gupta \& Ferguson (1987) exemplificam algumas heterodoxias que defendiam outros pontos de vista. Radin (1970 apud Gupta \& Ferguson, 1987:23), depois de se ter visto obrigado a contratar trabalhadores não treinados para levar a cabo o seu trabalho de campo, devido à grande escala do mesmo, encontrou nesta imposição uma vantagem, concluindo que a formação académica repercutia negativamente no estabelecimento de relações com os sujeitos de estudo, pois erguia uma barreira que dificultava o diálogo. Neste sentido, Radin (ib.idem) chega a conclusão de que "the essential qualification for an observer is that he posses the gift for establishing a direct an immediate contact with his source of information in as unobtrusive as possible manner"

Através do mestrado percebi também que muitas das reflexões que me tinham surgido ao longo dos primeiros anos de convivência e do período de filmagens em Porto Formoso, como os processos de activação patrimonial, de gentrificação e turistificação, entre outros, tinham sido amplamente estudados e analisados antropologicamente. Muitos dos fenómenos e conceitos que eu tinha identificado e descrito instintivamente, afinal tinham nome e história nas ciências sociais. O enquadramento teórico ajudou-me a organizar os pensamentos, detectar tendências, suprir lacunas e adensar reflexões, de forma a situar este trabalho de campo não só no corpus da antropologia, mas também nos processos de transformação do mundo e das relações de poder. As teorias sobre património de Kirshenblatt-Gimblett $(1995,1998,2004)$ e sobre as activações patrimoniais de Prats (2006), os trabalhos sobre o património e o mar de Elsa Peralta (2003, 2006, 2008), os conceitos de "dissonance" e "disinheritance" de Tunbridge \& Ashworth (1996), a modernidade líquida de Bauman (2000), os estudo de caso de Bordonaro (2007), de Fonseca (2007) e de Mendes (2008), a literatura de Corbin sobre os territórios costeiros $(1989,1995)$ e

$7 \quad$ O meu conhecimento do português e mais especificamente da variante micaelense progrediu consideravelmente, e a barreira linguística que se erguia no início foi ultrapassada. Se no início estava limitada a observar e registar apenas as formas de cultura que o olho podia ver, ao longo do tempo fui adquirindo maiores conhecimentos, fui sendo capaz de registar a informação de forma cada vez mais detalhada. Isto permitiu-me mergulhar em níveis mais profundos desta sociedade, ultrapassando a superficialidade inicial e recolhendo algumas das suas complexidades. 
as questões sobre a antropologia marítima em Portugal do professor Nunes (2001, 2003, 2008), entre outros, foram textos fundamentais para refletir, estruturar e construir a narrativa visual.

\section{VIII}

Depois do primeiro ano de seminários do mestrado, nasceu a minha filha e fiz uma pausa de um ano. Após o intervalo e já com as ideias novas da antropologia na minha bagagem, fiz uma nova incursão em Porto Formoso. Era Fevereiro de 2012, o meu namorado e a minha filha iam comigo. Apesar de ter passado 4 anos desde a última vez que estive na aldeia, as pessoas receberam-me calorosamente e vieram cumprimentar-nos como se de amigos de longa data se tratasse, mesmo aquelas pessoas com quem tinha tido menos contacto. $\mathrm{O}$ grau de intimidade que tinha criado com muitas das pessoas que filmei mantinha-se e, mais do que nunca, senti que a aldeia, como um todo, se sentia completamente à vontade com a minha pessoa e a minha câmara. Acho que esta ainda maior disponibilidade para o filme se deveu a dois factores. Por um lado, eu já tinha mostrado algum material anterior e depois de o verem juntos perceberam melhor o que se estava a fazer. Por outro lado, o facto de ter voltado mais uma vez, depois de quatro anos, reforçou a confiança mútua.

Há três aspectos que diferenciam estas filmagens de todas as anteriores. Nos últimos anos tinha revisto e tinha tentado editar o material filmado anteriormente muitas vezes, e estava ciente dos erros que não poderia voltar a cometer nas gravações: deixaria mais espaço entre as minhas perguntas e as suas respostas, deixaria mais tempo para eles falarem sem eu intervir, não cortaria logo depois de filmar, deixando respirar sempre a imagem, teria cuidados especiais com o som, sobretudo em exteriores, e com os planos em contraluz. Por último, decidi nesta viagem optar por usar apenas tripé. Nas filmagens anteriores tinha usado frequentemente a câmara na mão e o monopé para poder acompanhar ao instante acontecimentos inesperados e olhares escondidos, sem perder nenhum detalhe do espaço e da ação. Mas a minha técnica não era a melhor, (os planos ficavam instáveis, tremidos) e não tinha equipamento adequado (i.e um steadycam, um apoio de ombro), pelo que não tinha conseguido ainda fazer aqueles planos sequência orgânicos, contínuos, calmos, que caracterizavam alguns dos filmes de Jean Rouch. ${ }^{8}$ Por isso e tendo em conta que as filmagens que precisava agora (mais um depoimento, a nova paisagem, as obras na tasca) eram muito específicas e estavam mais planificadas e previstas, o tripé parecia a melhor opção.

Por outro lado, a transformação do porto tinha-se concluído: foi construída uma doca em cimento e, consequentemente, a actividade da pesca tinha melhorado, mas ao mesmo tempo a paisagem natural tinha-se deteriorado e o "castelo" tinha sido definitivamente abandonado. Isto dava um final claro ao documentário: era o fim dado pelas circunstâncias, pela vida, pelo tempo. Essa conclusão permitiu-me estruturar o filme claramente nos três actos dramáticos de introdução, desenvolvimento e desenlace.

Mas o aspecto que provavelmente marca a maior diferença entre estas filmagens e as anteriores é a perspectiva antropológica que agora se acrescentava à de visitante e à de documen-

8 Como indica Henley (2009:12) Rouch fez em plano sequência várias curtas-metragens sobre as cerimónias de possessão de espíritos em Níger, mas a forma mais elaborada deste tipo de filmagem foi a série de filmes que realizou sobre a vida cerimonial dos Dogon (Este do Mali) que começou em 1966 e continuou durante uma década. 
tarista. Sem dúvida, a leitura dos autores que referi anteriormente e de muitos outros textos antropológicos, apuraram o meu olhar, ajudando a centrar-me no que era essencial para acabar de concluir o filme. A minha posição saiu reforçada, e com uma maior segurança com respeito ao que procurava, ia colocando as questões essenciais, evitando a dispersão de temas que tinham caracterizado as filmagens anteriores. $\mathrm{O}$ meu interesse centrava-se, acima de tudo, em como as pessoas sentiam a transformação que de facto agora se manifestava na nova paisagem da aldeia, e como esta opção de progresso tinha afectado a sua identidade. Foram as melhores filmagens em Porto Formoso: os depoimentos que recolhi foram únicos. Sem eu ter de intervir, apenas guiando o foco e colocando as questões certas, eles manifestaram a contradição das identidades e da sua projeção no futuro tão discutido na antropologia de uma forma realmente lúcida e descontraída.

\section{IX}

Embora para o projecto final de mestrado pudesse optar por entregar apenas o filme e uma curta memória sobre o processo de construção do mesmo, eu optei por escrever uma dissertação que acompanhou o documentário, pois precisava de espaço para expor todas as questões que me surgiram após assistir aos seminários de antropologia. ${ }^{9}$ Precisei de 150 páginas para analisar, de uma perspectiva antropológica, todas as questões que os habitantes de Porto Formoso tinham discutido durante estes anos utilizando, por um lado, as minhas filmagens como diário etnográfico e, por outro, o blogue "acasadamosca" que entretanto tinha descoberto e onde se discutiam todo o tipo de assuntos: futebol, gastronomia, festas populares, atividades de lazer, mas também questões políticas, o peso da igreja na comunidade, as intrigas entre habitantes e com as aldeias vizinhas, e o que mais me interessava, as opiniões sobre o futuro do porto de pescas, coração da aldeia. ${ }^{10}$ Esta nova fonte de informação ampliou a minha percepção da comunidade significativamente. Maioritariamente anónimos, os comentários deixados no blog amplificaram e aprofundaram, como uma espécie de eco, muitos dos depoimentos que eu tinha recolhido junto dos pescadores que, por não serem anónimos, ficavam às vezes pela metade. A estrutura desta dissertação pensou-se, assim, como uma melodia polifónica, como uma recriação de um diálogo imaginário entre as palavras dos pescadores, os comentários virtuais do blogue e o corpus teórico da antropologia.

9 Título da dissertação: "Apanhados na rede. Considerações acerca das noções de progresso e modernidade na comunidade piscatória de Porto Formoso". Acessível no repositório da Universidade Nova de Lisboa, <http://run. unl.pt/handle/10362/10600>.

10 Ver <http://acasadamosca.blogspot.pt/>. O nome do blogue refere-se a uma paragem de autocarros de Porto Formoso onde as pessoas antigamente se juntavam para passar o tempo: ali se falava de futebol e de política, dos vizinhos e inimigos, de coisas sérias e brincadeiras e se discutiam todo o tipo de assuntos que diziam respeito à aldeia. É com este mesmo objectivo que, em 2005, em plena febre dos blogues em Portugal, nasce pela mão de Bruno Raposo, um jovem de 31 anos natural de Porto Formoso, a "casa da mosca virtual". Após a publicação do primeiro post em Julho desse ano, o blog cresce a uma velocidade estonteante. Desde o seu nascimento em 2005 até hoje, o Bruno Raposo, cujo nickname é "O Regedor" publica entre 2 e 5 posts por mês de temas diversos (cultura, política, festas, novidades, etc), mas sempre relacionados com o Porto Formoso. Em média, cada post suscita entre 40 a 80 comentários dos bloggers. Em Julho de 2006, A Casa da Mosca atingiu as cem mil visualizações e no mês de Julho de 2012 registava um total de 187.953, o que mostra que o blogue não só não tem perdido interesse, mas antes continua a crescer. 
A escrita da dissertação foi sem dúvida essencial para finalizar o meu filme. Depois de terminar de escrever a tese, sentei-me de novo na mesa de edição. O filme começou a surgir em Junho de 2012, oito anos depois de começar a filmar e depois de muitas tentativas de edição. Como se de uma catarse se tratasse, subitamente visualizei o filme como um todo. Trabalhei durante 15 dias sem pausa, não pela pressão dos prazos, mas antes porque não conseguia parar. A selecção de imagens, depoimentos e momentos de entre as mais de 60 horas de material bruto que tinha filmado e que até esse momento se tinha tornado num pesadelo, surgia agora naturalmente. A ordem das sequências aparecia clara perante mim e a história fluía quase por si só. Houve três factores que considero essenciais para explicar este processo. Em primeiro lugar, a estrutura da escrita na dissertação serviu de base para a estrutura da narrativa visual no documentário, ao ponto de, algumas das frases da voz off terem saído directamente da tese. Em segundo lugar, o facto de ter tido, nessa mesma dissertação, espaço onde incluir, quer todas as reflexões que me apareceram ao longo destes nove anos quer os aspectos que pelo seu conteúdo político ou privado não queria expor no meu filme. O filme podia agora voar mais livremente, sem o peso de ter de apresentar todas as pessoas e de contar todos os acontecimentos que registei. Depois de escrever a dissertação, tinha liberdade para poder centrar-me no que me interessava do ponto de vista visual, deixando de lado as polémicas típicas dos meios pequenos onde os poderes e as pessoas se confundem.

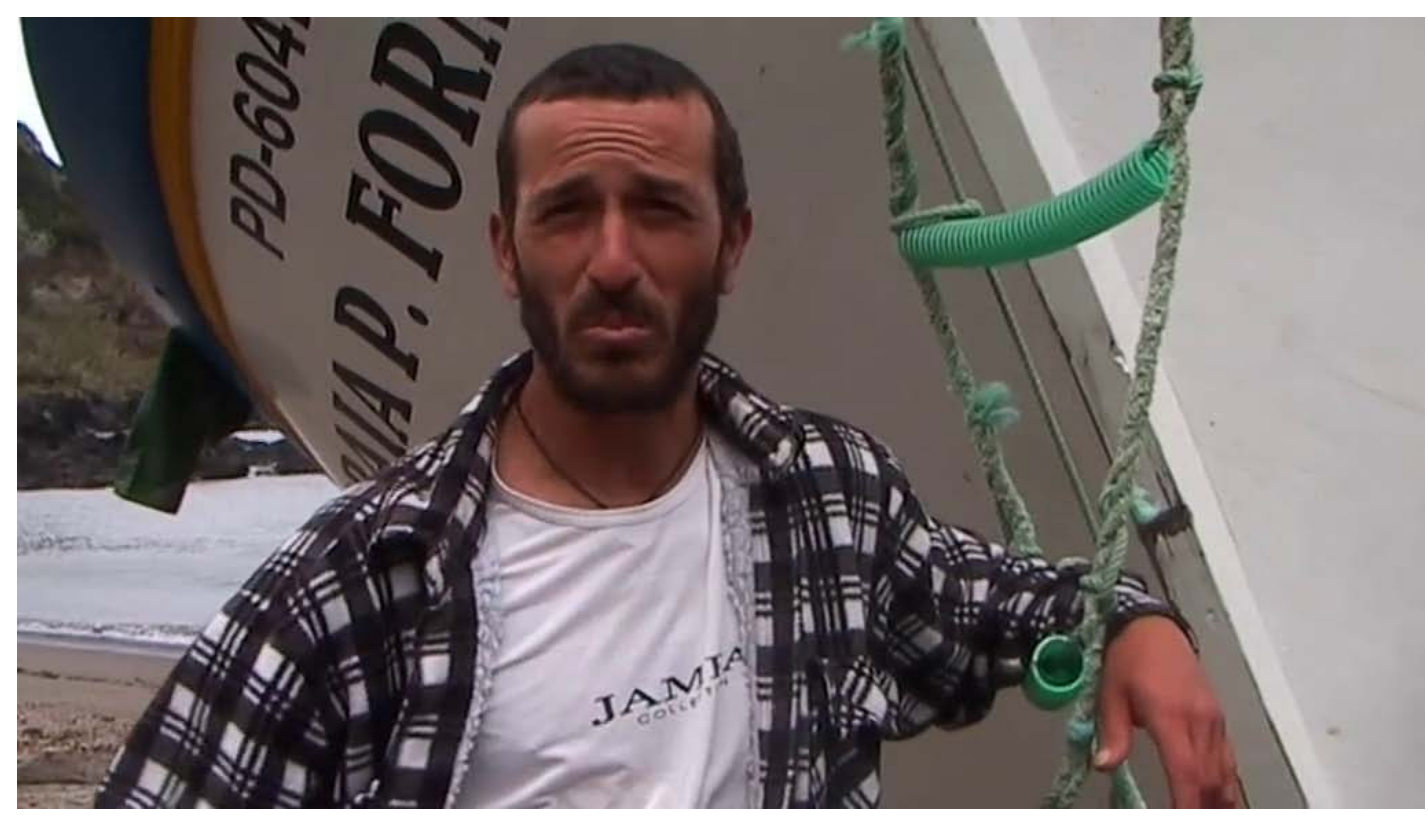

Excerto 5: Exemplo de entrevista não incluída no documentário final, por respeito com a pessoa entrevistada, devido ao conteúdo polémico e "intriguista" da mesma,. Porém, esta entrevista foi analisada na dissertação teórica.

Em terceiro lugar e se calhar o mais importante, perdi o medo de assumir a minha presença no filme. Por um lado, o contacto com as teorias antropológicas, que giram em torno da análise da relação entre o Eu e o Outro, deram-me uma nova perspectiva. Por outro lado, as orientações da professora Catarina Alves Costa, o contacto com a história do filme etnográfico e os filmes que no seu seminário de filme etnográfico foram vistos e analisados, abriram-me o caminho. Neste sentido, um dos filmes que mais me influenciaram foi "El cielo gira", da realizadora espanhola Mercedes Alvarez. ${ }^{11}$ Neste documentário, a realizadora faz uma viagem às

11 "El cielo gira" (2004). Realizada pela espanhola Mercedes Alvarez, conta o regresso da realizadora às suas 
suas origens, usando a sua própria voz na primeira pessoa para acompanhar o que parecem ser os últimos respiros da aldeia onde nasceu, antes do seu desaparecimento. Sem nunca abandonar o tom intimista, a autora faz um retrato do tempo universal da ruína, do transe do desaparecimento. Esse filme fez-me pensar que se essa experiência conjunta de tempo biográfico (o meu e o dos habitantes da aldeia) e de memória e vivência colectiva pudessem projectar-se sobre um tempo profundo, o meu filme valeria a pena. $\mathrm{E}$ para que isso acontecesse, o elo de ligação deveria ser o meu relato, a minha voz. Por isso, se na dissertação foi feita uma análise e uma reflexão teórica sobre as questões de identidade no passado, no presente e no futuro desta comunidade, agora no documentário passaria a relatar a experiência pessoal que supôs para mim os longos anos de convivência com estas pessoas. Enquanto na dissertação procurei sempre manter a objectividade, no filme mergulhei na minha própria subjectividade: contra a ideia inicial de apagar a minha presença do filme, passei a querer incluir a minha própria voz, em primeira pessoa e em espanhol, minha língua materna. Através deste elemento eu assumia perante o público a minha condição autoral.

"Reflexivity [...] referred to a process whereby the film- maker made clear to the audience, within the body of the film, through devices such as voice-over or title cards, how their personal subjectivity had come into play in the making of the film [...] Rather than aspire to some illusory objective representation, they were content to allow the relationships through which a film was being made to be revealed directly in the filmic text itself. (Henley 2009:11)

O filme contaria a forma como eu vivi os anos de contacto com esta comunidade e a relação da minha história com a história dos seus habitantes, projetando estes tempos biográficos sobre o tempo mais profundo da transformação. Porem, na articulação de todos os tempos, procurei sempre adoptar uma "postura de humildade perante o mundo" tal e como defende David MacDougall: sem deixar de assumir a responsabilidade pelo seu trabalho autoral, o cineasta deveria procurar desenvolver o seu trabalho pessoal em colaboração com os sujeitos filmados, respeitando os indivíduos cujo mundo tomou a liberdade de representar (Henley 2009: 21). Esta opção resolveu muitos dos problemas de edição que tinha encontrado até esse momento, mas mais importante, permitiu-me fazer o filme que, sem saber, sempre quis fazer e que apresentei na Mostra de Filme Etnográfico de Vila Real (2013).

\section{$\mathbf{X}$}

Depois de entregar o filme com a dissertação, "Apanhados na rede" teve a sua primeira estreia em Junho de 2013, no 13th International Festival of Ethnographic Film in Edinburgh, organizado pela Royal Anthropological Institute of Great Britain \& Ireland (RAI) . Para a estreia, retoquei o filme com a ajuda de amigos da área:, o Tó Trips para a música original, o Sérgio Gregorium para a pós-produção de som, a Raquel Castro para os acabamentos finais da edição. O filme acabaria por ter 58 minutos, em vez dos 70 iniciais. A recepção não foi um sucesso. Se por um lado o filme foi exibido num horário péssimo e numa sessão onde era o ultimo de três filmes de uma hora cada, o ambiente do festival era muito académico e a maioria dos filmes estavam filmados em lugares muito mais exóticos do que o meu: favelas na Índia, tribos na Nigéria, emigrantes no Nepal eram alguns dos temas dos documentários. Como reconhecem

origens para contemplar a extinção de uma aldeia, ao mesmo tempo que tenta recuperar as imagens do lugar quando ainda transbordava vida, quando, em princípios do século, a aldeia contava com 400 habitantes (<http://www. imdb.com/title/tt0443946/>). 
Gupta \& Ferguson na sua crítica ao confinamento local da etnografia, há lugares mais plausíveis para serem escolhidos para o trabalho de campo que outros:

Although anthropologists no longer think in terms of natural or undisturbed states, it remains evident that what many would deny in theory continues to be true in practice: some places are much more "anthropological" than others according to the degree of Otherness from an archetypical anthropological "home". (1987: 13)

É claro que fiquei um bocado desiludida, pois era a primeira vez que mostrava publicamente o meu trabalho, mas o mais importante para mim era mostrar o filme em Porto Formoso e após voltar de Edimburgo, consegui pela primeira vez financiamento para viajar aos Açores. ${ }^{12}$ Organizei as coisas para estrear o filme na altura das festas da aldeia, Nossa senhora de Graça, que têm lugar no início de Setembro. Falei com a comissão das festas, que aceitou mostrar o filme e providenciou um espaço e cadeiras. Tratava-se da Casa da cultura, que se encontrava em construção e tinha no seu interior pouco mais do que paredes de cimento. Apesar da má qualidade do espaço, acabei por decidir avançar com o mesmo, pois a única alternativa com melhores condições era o Cine Teatro de Ribeira Grande, situado a uns $20 \mathrm{~km}$ da aldeia, demasiado longe para os habitantes que não tinham carro. Cheguei a São Miguel uma semana antes. Falei com as pessoas da aldeia e com amigos de fora, distribuí cartazes e postais pela freguesia, divulguei pelas redes sociais e falei, claro, com os protagonistas para assistirem. Eles é que não podiam faltar. E prometeram não o fazer.

No dia da estreia e apesar do meu medo sobre a adesão das pessoas, a verdade é que a sala encheu: foram 180 cadeiras e muitas pessoas em pé. Veio quase toda a aldeia, velhos, crianças, pescadores, lavradores, homens, mulheres e muita gente de fora, jornalistas, amigos, agentes culturais, pessoas da política. A verdade, no entanto, é que os protagonistas não apareceram. Quando liguei ao Paulo Jorge, um dos pescadores que mais aparecia no filme, a sua filha atendeu: disse-me que o seu pai estava a arranjar o quintal (às oito da noite). Os outros não consegui contactar. Uns poucos apareceram no meio do filme e outros apenas no fim. O mestre Ricardo, outro dos protagonistas, chegou no fim e veio falar comigo. Acabou por me explicar: não queria ver o filme à frente de toda a aldeia porque sabia que iria chorar. Percebi. Ao longo destes anos, o mestre Ricardo passou de comprar um barco novo a vendê-lo para trabalhar nas obras, tudo porque as obras no porto não foram feitas a tempo, devido às políticas, economias e intrigas típicas de qualquer empreendimento público. Durante o filme, eu sentei-me na última fila. Estava muito nervosa e durante toda a projecção tive medo de que as pessoas se começassem a levantar e sair. Também não me atrevia a olhar para as caras deles durante o visionamento do filme, com medo de ver expressões contrariadas, aborrecimento. Só comecei a relaxar quando vi que iam ficando cada vez mais calados, mais atentos e que a sala não só não esvaziava como ficava cada vez mais cheia. Ouviam-se os murmúrios das pessoas, que comentavam e apontavam para o ecrã ao reconhecer amigos e familiares, pessoas que tinham crescido, envelhecido ou morrido: riam-se com muitas imagens, ficavam silenciosos com outras, mas nunca indiferentes. Até ao fim do filme não sabia qual seria a recepção, mas o meu medo dissipou-se rapidamente. Após um longo aplauso, as pessoas vieram ter comigo, como se de um casamento se tratasse, para dar os parabéns, para me expressar como se arrepiaram, riram, lembraram e gostaram do filme: a aldeia estava em festa! Os amigos e espectadores de fora também gostaram, falavam da honestidade, da transparência, da lucidez das pessoas que falavam e da capacidade de mostrar

12 Cortesia da revista Up, da companhia aérea TAP, que prepara um artigo sobre a aldeia e a estreia do filme na mesma, a ser publicado no próximo número de Dezembro (2013) e que estará disponível em todos os voos da TAP. 
opiniões divergentes, sem tomar partido em nenhuma: descreviam o filme como uma história de amor com a aldeia. Mas o que mais me tocou nessa noite foi ver como os espectadores iam dar os parabéns aos pescadores e habitantes que tinham participado no filme: diziam-lhes que tinham falado bem, que fizeram um grande papel. O reconhecimento era sobretudo para eles e isso foi fundamental. Foi o dia mais importante, o dia pelo que tudo valeu a pena.

No dia a seguir à estreia e ainda com as emoções à flor de pele, viajei directamente para Vila Real, onde mostraria o filme perante um público completamente diferente, um público principalmente vindo da antropologia. Depois da experiência em Edimburgo estava desconfiada, mas a verdade é que o filme foi bem recebido. Se calhar o facto de ser um público principalmente português, (e também brasileiro), ajuda na percepção desta sociedade. Apesar de não conhecerem a aldeia, as pessoas riram e ficaram em silêncio, arrepiaram-se e aplaudiram. Os adjectivos repetiam-se, honesto, verdadeiro, lúcido: história de amor. Depois desta exibição fiquei bem mais segura em relação ao filme.

Um mês depois, em Outubro, o meu documentário foi para o Festival de Cinema ambiental de Seia. Embora eu tivesse feito a inscrição do filme, nunca pensei que fosse seleccionado, pois nunca tinha pensado no meu filme em termos ambientais, nem nunca foi a minha intenção fazer um filme sobre o ambiente. A verdade é que, quando agora revejo o filme, vejo sem dúvida uma abordagem a questões transversais às discussões ambientais. Este filme fala, e muito, sobre o ambiente embora não da poluição, das fábricas e carros, da falta de água e doutras ideias associadas tipicamente às questões ambientais. Mais uma vez, o filme foi mostrado perante um público bem diferente, pessoas do interior de Portugal, estudantes, pessoas ligadas ao ambiente. E mais uma vez, o filme foi bem recebido e as pessoas vieram falar comigo no fim do filme. Uma semana mais tarde, ganhou o prémio "Camacho Costa" para o melhor documentário longa-metragem da competição Lusofonia.

\section{Conclusões}

Dificilmente terei a oportunidade de voltar a acompanhar uma história durante tantos anos. É preciso que muitas circunstâncias convirjam e aconteçam na altura certa para que as histórias possam ser registadas longitudinalmente e contadas de uma forma coerente ao público. É preciso ter o tempo, a paciência e a disponibilidade e, numa época em que o tempo voa, é cada vez mais difícil contar com qualquer uma destas três condições. É preciso ter alguma ajuda financeira, porque ninguém vive do ar, mas é quase impossível arranjar financiamento para este tipo de produções e fazer outro filme sem nenhum apoio seria para mim desmoralizador. E é preciso ter concentração: o confronto com horas intermináveis de material e com uma história cujo desenvolvimento não se controla é intelectualmente esgotante. Neste sentido, a antropologia foi sem dúvida essencial para a finalização do meu documentário com sucesso. Dito isto, não tenho qualquer dúvida em afirmar que, como o prato que se faz ao sabor de um lume brando durante horas, o filme que se faz com tempo é único. E numa altura da história em que, contra o aceleramento, contra o imediato e o mediatismo global, surgem movimentos de slow food, slow cities, slow travel e slow schools, defendo veementemente a existência de um movimento correspondente na indústria do cinema, que poderia chamar-se slow filming. Os documentaristas devem lutar pelo direito de filmar com tempo e não seguindo planos de produção intensivos e irracionais, impostos pelas limitações financeiras, que obrigam a concentrar a experiência do 
contacto, o conhecimento e o convívio com outras comunidades em três semanas. Ver a realidade transformar-se perante os teus olhos, sentir a vida mudar com a história, entrar na vida dos outros e deixar os outros entrar, devagar, é, sem dúvida, uma experiência imensamente rica, pessoal e profissionalmente. Acredito firmemente que é uma experiência que qualquer realizador deveria tentar, pelo menos, uma vez na vida.

To pull off a successful longitudinal documentary really means having the stars align on so many fronts - no wonder it doesn't happen too often. But when it does, for the viewer and the filmmaker, there's no more compelling or moving a form. No other kind of fiction or documentary filmmaking can match its power to transport us deeply into the lives and experiences of others different from ourselves. And that is something that we need in this world now more than ever. (James 2008)

\section{REFERÊnCIAS}

Bauman, Zygmunt. 2000. Modernidade líquida. Rio de Janeiro: Zahar.

Bordonaro, Lorenzo Ibrahim. 2007. Living at the margins. Youth and modernity in the Bijago Islands (Guinea-Bissau). Lisboa: ISCTE. Tese de doutoramento.

Corbin, Alain. 1989. O território do vazio: a praia e o imaginário social. São Paulo: Companhia das Letras.

1995. L'avènement des loisirs 1850-1960. Paris: Aubier.

Fonseca, Inês .2007. Trabalho, Identidades e Memórias em Aljustrel - "Levávamos a foice logo p’ra mina", s/1., 100 Luz.

Gupta, Akhil \& Ferguson, James.1987. "Discipline and Practice: the Field as Site, Method and Location in Anthropology". Pp.1-46 in Antrhopological Locations. Boundaries and Grounds of a Field ScienceA. Gupta \& J. Ferguson (eds.). Berkeley: University of CAlifornia Press.

Henley, Paul. 2009. "In denial: authorship and ethnographic film-making". Pp. 101-126 in Imagem-Conhecimento: antropologia, cinema e outros diálogos, ed. Andréa Barbosa, Edgar Teodoro da Cunha and Rose Satiko G. Hikiji,. Portugal: Campinas: Papirus Press. eScholarID:3b3669.

James, Steve. 2008. The Decline of the Longitudinal Documentary. New York: IFC Entertainment. Retrieved October 15th, 2013 (http://www.ifc.com/fix/2008/05/the-decline-of-the-longitudina)

Kirshenblatt-Gimblett, Bárbara. 1995. “Theorizing Heritage”. Ethnomusicology, 39 (3): 367380.

1998. Destination Culture: Tourism, Museums, and Heritage. Univ. California Press.

2004. From ethnology to heritage: The role of the Museum. SIEF Keynote, Marseille.

Malinowski, Bronislaw.1997 [1922]. "Os argonautas do Pacífico Ocidental - Introdução: objecto, método e alcance da investigação". Ethnologia (nova série), 6-8: 17-38.

Mead, Margaret. 1995. "Visual anthropology in a discipline of words". Pp.3-10 in Principles of Visual Anthropology, P. Hockings (ed). Berlin \& New York: Mouton de Gruyter.

Mendes, Paulo. 2008. “Pescadores, Camponeses, Empresários, Turistas e Percepção do Ambiente na Costa Altenejana: uma Leitura Cronológica e Etnográfica”. Pp. 183 - 207 in Culturas Maritimas em Portugal, Francisco Oneto Nunes, (coord). Lisboa: âncora.

Nunes, Francisco Oneto. 2001. "A Antropologia Marítima em Portugal - um breve excurso", Pp. 29-40 in História do Trabalho e das Ocupaçôes, Nuno Luís Madureira (coord.) e Inês Amorim (org.), , Vol. II, As Pescas. Oeiras: Celta Editora. 
.2003. “O Trabalho faz-se Espectáculo: a pesca, os banhos e as modalidades do olhar no litoral central”, Etnográfica, Vol. VII (1): 131-157.

2008 "Introdução"Pp. 5-14 InCulturas Maritimas em Portugal , F. Oneto Nunes (org).. Lisboa: Âncora Editora.

Peralta, Elsa. 2003. “O mar por tradição: o património e a construção das imagens do turismo”. Horizontes Antropológicos: Antropologia e Turismo. 9 (20): 83-96.

2006 "Memória do mar: património marítimo e (re)imaginação identitária na construção do local”. Pp.75-84 in Patrimónios e Identidades: Fiç̧ões Contemporâneas E. Peralta \& M. Anico (Orgs.), Oeiras:Celta.

2008. "O Mar como património. Considerações acerca da identidade nacional portuguesa” Pp. 71 -92 in Culturas Maritimas em Portugal, Francisco Oneto Nunes (coord.). Lisboa: Âncora.

Prats, Llorenç. 2006. “Activações turístico-patrimoniais de carácter local”. Pp 191-200 in Patrimónios e Identidades: Ficçôes Contemporâneas E. Peralta \& M. Anico (Orgs.), Oeiras:Celta.

Richardson, R. J.1999. Pesquisa social: Métodos e técnicas. 3. ed. São Paulo: Atlas.

Ribeiro, José da Silva. 2007. "Jean Rouch - Filme etnográfico e Antropologia Visual” Doc Online, n.03, Dezembro 2007 (http://www.doc.ubi.pt/03/artigo_jose_ribeiro.pdf).

Tunbridge, John.E. \& Asworth, Gregory John.1996. Dissonant Heritage: The Management of the Past as a Resource in Conflict. Chichester: Wiley.

\section{LONGITUDINAL DOCUMENTARY: THE IMPORTANCE OF SLOW FILMING}

In the form of a kind of a shooting log, the present article recounts the nine years that went by since the author's first encounter with the community, until the premiere of the documentary filmed along this time, when the images were finally "given back" to the portrayed characters. The article examines the role of anthropology in the process of film-making and, based on the author's practical experiences, discusses the advantages and disadvantages of recording the same subjects during such a long time.

Keywords: longitudinal documentary; slow filming; visual anthropology

Recebido em: 2013-11-27

Aceito em: 2014-03-07 